\title{
Changes in markers of bone metabolism during dexamethasone treatment for chronic lung disease in preterm infants
}

\author{
P C Ng, C W K Lam, G W K Wong, C H Lee, P S Cheng, T F Fok, I H S Chan, E Wong, \\ $K$ Cheung, S Y Lee
}

See end of article for authors' affiliations

Correspondence to: Professor $\mathrm{Ng}$, Department of Paediatrics, Level 6 , Clinical Science Building, Prince of Wales Hospital, Shatin, NT, Hong Kong pakcheungng@cuhk.edu.hk

Accepted 23 August 2001

\begin{abstract}
Aim: To characterise the change in serum and urinary bone markers in the early postnatal period, and to assess the effect of systemic corticosteroid on bone metabolism in preterm infants.

Methods: Bone formation was quantified by measurement of serum concentrations of bone specific alkaline phosphatase (BALP) and osteocalcin. Bone resorption was measured by monitoring creatinine adjusted urinary deoxypyridinoline (Dpd) concentration. Blood and urinary samples were collected from corticosteroid treated infants $(n=19)$ immediately before the start $\left(T_{\text {d.pre }}\right)$, three weeks after the start $\left(T_{\text {dend }}\right)$, and two $\left(T_{\text {d-post } 2}\right)$ and four weeks $\left(T_{\text {d-post } 1}\right)$ after the end of the dexamethasone course. Untreated patients $(n=30)$ had specimens taken at week $3\left(T_{w k-3}\right), 6\left(T_{w k-6}\right), 8\left(T_{w k-8}\right)$, and $10\left(T_{w k-10}\right)$ of postnatal age. Results: Serum concentrations of BALP and osteocalcin at $T_{\text {dend }}$ were significantly lower than pretreatment levels and the levels at the corresponding time point $\left(T_{w k-6}\right)$ of the non-treatment group. In contrast, urinary Dpd concentration at $T_{\text {dend }}$ was not significantly decreased compared with the pretreatment level. However, it was significantly lower than the urinary Dpd concentration at $T_{\text {wk. }}$ of the non-treatment group. The rate of increase in lower leg length was significantly higher in the non-treatment group between weeks 3 and 6 than in the corresponding period during dexamethasone treatment in the corticosteroid group.

Conclusion: Systemic corticosteroid causes appreciable suppression of serum BALP and osteocalcin and, to a lesser extent, urinary Dpd. The results suggest that corticosteroid inhibits bone growth mainly by decreasing bone formation.
\end{abstract}

$\mathrm{P}$ reterm, very low birthweight (VLBW) infants are at increased risk of growth impairment and osteopenia in the perinatal period. ${ }^{1-4}$ The latter condition is probably associated with deficient intake of mineral substrates including calcium and phosphorus. ${ }^{2}{ }^{4}$ Although most infants with osteopenia are clinically asymptomatic and biochemical disturbances are self limiting, a minority of them develop serious complications, including radiological rickets and nontraumatic fractures. The use of systemic corticosteroid for long term treatment of clinical disorders in adult patients has been shown to decrease bone formation and not change or increase bone resorption, ${ }^{5}$ which may ultimately result in acute bone loss or pathological fracture. Thus the administration of high dose dexamethasone, which is commonly used to facilitate weaning from mechanical ventilation and treatment of bronchopulmonary dysplasia (BPD), ${ }^{7}$ may pose a further risk of bone loss to preterm infants. Yet, very little is known about the effect of corticosteroid on bone metabolism in this category of patients. This study is therefore designed to characterise changes in concentrations of specific circulating and urinary biochemical markers of bone metabolism before, during, and after dexamethasone treatment in VLBW infants, in an attempt to provide further insights into the underlying pathogenic process. Bone specific alkaline phosphatase (BALP), a tetrameric glycoprotein located on the surface of osteoblasts, has a key role in bone mineralisation. Osteocalcin, a noncollagenous protein of the bony matrix secreted specifically by osteoblasts, correlates closely with osteoblastic activity. These two markers were used to assess bone formation in this study. In addition, urinary deoxypyridinoline (Dpd), a non-reducible cross link of collagen exclusively derived from bone, was used as a marker of collagen degradation and bone resorption. ${ }^{8}$

\section{PATIENTS AND METHODS Study population}

Nineteen preterm VLBW infants who were admitted to the neonatal unit at Prince of Wales Hospital, Hong Kong between September 1997 and January 1999 and received systemic dexamethasone for treatment of $\mathrm{BPD}$, were prospectively enrolled in the study. In addition, 30 VLBW infants who did not receive corticosteroid treatment within the same study period were used for comparison. Preterm infants with major congenital or skeletal abnormalities or chromosomal disorders, and those who received postnatally inhaled corticosteroid were excluded.

\section{Processing of specimens and anthropometric measurements}

Blood and urinary samples were collected from corticosteroid treated infants immediately before the start $\left(\mathrm{T}_{\mathrm{d}-\mathrm{pre}}\right)$, three weeks after the start $\left(\mathrm{T}_{\mathrm{d}-\mathrm{end}}\right)$, and two $\left(\mathrm{T}_{\mathrm{d} \text {-post } 2}\right)$ and four weeks $\left(\mathrm{T}_{\mathrm{d} \text {-post } 4}\right)$ after the end of dexamethasone treatment. Untreated patients had blood and urinary specimens taken at week 3 $\left(\mathrm{T}_{\mathrm{wk-3}-3}\right), 6\left(\mathrm{~T}_{\mathrm{wk}-6}\right), 8\left(\mathrm{~T}_{\mathrm{wk}-8}\right)$, and $10\left(\mathrm{~T}_{\mathrm{wk}-10}\right)$ of postnatal age. Serum BALP was quantified by precipitation with wheatgerm lectin, and serum osteocalcin by fluorescence enzyme immunoassay (Pharmacia Upjohn Diagnostics AB, Uppsala, Sweden). Urinary Dpd was measured by chemiluminescence enzyme immunoassay (ACS analyser, Chiron Diagnostics Corp, Norwood, Massachusetts, USA), and urinary creatinine

Abbreviations: BALP, bone specific alkaline phosphatase; Dpd, deoxypyridinoline; VLBW, very low birth weight; BPD, bronchopulmonary dysplasia. 
by the Jaffe (kinetic) method (Hitachi 911 autoanalyser, Roche Diagnostics Corp, Indianapolis, Indiana, USA). The interassay coefficients of variation for serum BALP and osteocalcin and urinary Dpd and creatinine were: $4.1 \%$ at 83 $\mathrm{U} / \mathrm{l}, 5.6 \%$ at $37.8 \mathrm{ng} / \mathrm{l}, 6.7 \%$ at $23.7 \mathrm{nmol} / \mathrm{l}$, and $4 \%$ at $7.5 \mathrm{l}$ $\mathrm{mmol} / \mathrm{l}$ respectively. Urinary Dpd concentrations were subsequently corrected for creatinine concentration. All blood and urinary specimens were collected in the morning between 0800 and 1200, and coincided with the weekly measurements of haemoglobin and liver function in order to minimise disturbance of these infants. Lower leg length was also measured weekly at the bedside using a neonatal knemometer. ${ }^{10}$

\section{Dexamethasone dose}

The decision to start systemic dexamethasone treatment was made by the attending neonatologists. The neonatal unit guidelines were: (a) ventilator dependence or oxygen requirement of more than $40 \%$ after 2 weeks of age; (b) absence of any treatable cause that might prevent successful weaning, such as infection or patent ductus arteriosus; (c) absence of any major contraindication for starting corticosteroid treatment, such as severe hypertension, uncontrolled hyperglycaemia, massive gastrointestinal haemorrhage, or recent abdominal surgery. Each infant was given a three week dose tapering course of dexamethasone (dexamethasone sodium phosphate; Weimer Pharma, Rastatt, Germany) starting with $0.6 \mathrm{mg} / \mathrm{kg} /$ day in the first week. The initial dose was then halved and quartered in the second, and third week of treatment respectively. ${ }^{7}$ Dexamethasone was given as a bolus intravenous injection in the morning.

\section{Enteral and parenteral nutrition}

Preterm VLBW infants were routinely started on intravenous dextrose after birth to prevent hypoglycaemia. Parenteral nutrition, 6\% TrophAmine (McGaw Inc, Irvine, California, USA) and 20\% Intralipid (Kabi Pharmacia AB, Stockholm, Sweden), was started on day 3 of life. Oral milk feeds were usually introduced between day 5 and 7 , and the quantity of milk was cautiously increased by $0.5-1 \mathrm{ml} /$ hour/day depending on tolerance. VLBW infants were fed mothers' milk whenever possible, but preterm commercial milk formula could also be used if the parents preferred. They were closely monitored for the occurrence of vomiting, abdominal distension, and volume of gastric residuals. Strict guidelines were provided for neonatologists with regard to stopping and restarting of enteral feeding and hyperalimentation. Oral vitamin D (400 IU/day) and oral sodium hydrogen phosphate supplements (1 $\mathrm{mmol} / \mathrm{kg} /$ day in six divided doses) were started once the infant was tolerating full enteral feeding. Our unit policy is to maintain the plasma phosphate concentration at $1.8-2.2$ $\mathrm{mmol} / \mathrm{l}$.

\section{Ethics}

Ethical approval for the study was obtained from the clinical research ethics committee of the Chinese University of Hong Kong. Informed parental consent was obtained for each case.

\section{Statistical analysis}

The descriptive statistics on clinical details and concentrations of serum and urinary bone markers are expressed as median and interquartile range. Mann-Whitney $U$ test or $\chi^{2}$ test was used to compare the clinical characteristics, anthropometric variables, initial rate of increase in lower leg length, and concentrations of serum and urinary bone markers before dexamethasone treatment $\left(\mathrm{T}_{\mathrm{d}-\mathrm{pre}}\right)$ and at the corresponding time point in the non-treatment group $\left(\mathrm{T}_{\mathrm{wk}-\mathrm{s}}\right)$. Multilevel models (mixed effects models) ${ }^{11}$ were used to assess the longitudinal change in growth of the lower leg and concentrations of serum and urinary bone markers at different stages of dexamethasone treatment in the corticosteroid group, and at different time points in the non-treatment group. Moreover, these models were also used to compare the concentrations of the bone markers at the corresponding time points between infants who received dexamethasone and those who did not $\left(\mathrm{T}_{\mathrm{d}-\text { end }} v \mathrm{~T}_{\mathrm{wk}-6^{\prime}} \mathrm{T}_{\mathrm{d}-\text { post2 } 2} v \mathrm{~T}_{\text {wk- }-8^{\prime}}\right.$ and $\mathrm{T}_{\mathrm{d}-\text { post4 }} v$ $\mathrm{T}_{\mathrm{wk}-10}$ ). Multilevel modelling is an extension of the ordinary least squares regression, but takes into account the within and between subject heterogeneity. ${ }^{11}$ For longitudinal data, multilevel models allow for measurements made at unequal intervals and with a varied number of measurements-that is, subjects who may have one or several measurements. The models were fitted by using the restricted iterative generalised least square algorithm of MLn for Windows software

Table 1 Clinical characteristics of very low birthweight infants, one group of which received corticosteroid $(n=19)$ and the other group did not $(n=30)$

\begin{tabular}{|c|c|c|}
\hline & $\begin{array}{l}\text { Corticosteroid group } \\
(n=19)\end{array}$ & $\begin{array}{l}\text { Non-treatment group } \\
(\mathrm{n}=30)\end{array}$ \\
\hline Gestational age (weeks) & $27.8(26.7-29.2)$ & $29.6(29.1-31.1)^{* *}$ \\
\hline Birth weight (g) & $1038(884-1192)$ & $1146(998-1364)$ \\
\hline Male to female ratio (n) & $12(63 \%): 7(37 \%)$ & $16(53 \%): 14(47 \%)$ \\
\hline Antenatal dexamethasone (doses) & $2(2-4)$ & $2(2-4)$ \\
\hline $\begin{array}{l}\text { Duration between the last dose of antenatal } \\
\text { dexamethasone and delivery }(\mathrm{h}) \\
\text { Mode of delivery: }\end{array}$ & $55(15-115)$ & $29(9-68)$ \\
\hline Caesarean section : instrumental : normal & $9(47 \%): 0(0 \%): 10(53 \%)$ & $23(77 \%): 1(3 \%): 6(20 \%)^{*}$ \\
\hline \multicolumn{3}{|l|}{ Apgar scores } \\
\hline $1 \mathrm{~min}$ & $5.8(4.0-7.3)$ & $6.5(3.9-8.0)$ \\
\hline $5 \mathrm{~min}$ & $9.0(8.0-9.0)$ & $9.0(7.0-10.0)$ \\
\hline $\begin{array}{l}\text { Age at start of postnatal dexamethasone treatment } \\
\text { (days) }\end{array}$ & 25 (17-37) & - \\
\hline Age at start of multivitaman preparation - Vimax (days) & $35(25-53)$ & $37(27-50)$ \\
\hline Age at start of oral phosphate supplement (days) & $33(25-54)$ & $35(27-47)$ \\
\hline Age at which full enteral feeding achieved (days) & $33(25-53)$ & $38(27-56)$ \\
\hline Duration of mechanical ventilation (days) & $28(13-59)$ & $7(2-16)^{* *}$ \\
\hline Duration of oxygen dependency (days) & $37(22-63)$ & $8(2-24)$ ** \\
\hline Duration of hospital stay (days) & $103(84-118)$ & $71(58-100)^{* *}$ \\
\hline \multicolumn{3}{|l|}{ Outcome } \\
\hline Alive : dead & $19(100 \%)$ : $0(0 \%)$ & $29(97 \%): 1(3 \%)$ \\
\hline
\end{tabular}




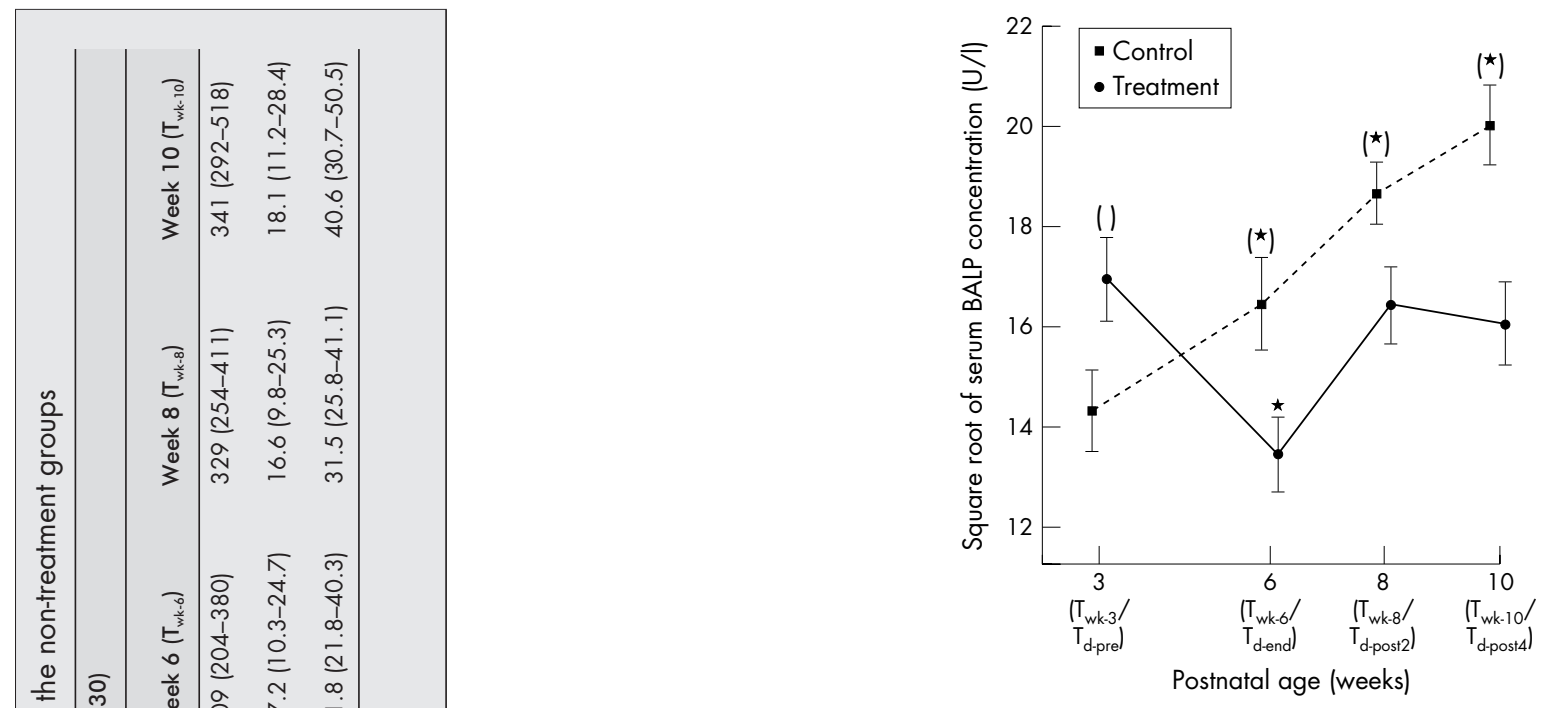

Figure 1 Serum bone specific alkaline phosphatase (BALP) concentrations (U/I; square root) in very low birthweight infants receiving corticosteroid or not over the study period. The asterisks indicate significant increase or decrease in serum BALP concentration compared with the pretreatment $\left(T_{d \cdot p r e}\right)$ or week $3\left(T_{w k 33}\right)$ levels within the same group. The parentheses indicate a significant difference in serum BALP concentration between the two groups when the corresponding time periods are compared. Results are expressed as mean and SEM.

package, version 2.0 (Institute of Education, University of London, UK). The rest of the statistical tests were performed by SPSS for Windows (Release 9.0 SPSS Inc, Chicago, Illinois, USA). The statistical analysis was performed on raw, square root, and logarithmically transformed results where appropriate in order to correct the skewness of the data. The level of significance was set at $5 \%$ in all comparisons.

\section{RESULTS}

Nineteen VLBW infants who required dexamethasone for treatment of BPD were enrolled in the study. All infants completed a full course, and their results were compared with those of 30 VLBW infants who did not receive the drug. Table l summarises the clinical characteristics of the corticosteroid and non-treatment group. More infants in the non-treatment group were born by caesarean section $(p<0.05)$. Corticosteroid treated infants had significantly lower gestational ages at birth $(p<0.001)$ and longer duration of mechanical ventilation $(\mathrm{p}<0.001)$, oxygen supplementation $(\mathrm{p}<0.001)$, and hospital stay $(\mathrm{p}<0.001)$.

The median age at which dexamethasone treatment was started was 25 days $\left(\mathrm{T}_{\text {d-pre }}\right)$, and this time point corresponded closely to week 3 of postnatal age $\left(\mathrm{T}_{\mathrm{wk}-3}\right)$ in the non-treatment group. Table 2 summarises the changes in concentration of serum and urinary bone markers over the first 10 weeks of life. Figures 1-4 show the concentrations of serum BALP and osteocalcin, creatinine adjusted urinary Dpd concentrations, and rate of increase in lower leg length respectively at various time points.

\section{Within group comparison}

\section{Corticosteroid group}

At the end of the three week course of dexamethasone treatment $\left(\mathrm{T}_{\text {d-end }}\right)$, the markers of bone formation, serum BALP and osteocalcin concentrations, were significantly lower than pretreatment $\left(\mathrm{T}_{\mathrm{d}-\mathrm{pre}}\right)$ levels $(\mathrm{p}<0.0005$ and $\mathrm{p}<0.0001$ respectively). Serum concentrations of BALP and osteocalcin at $\mathrm{T}_{\mathrm{d} \text {-post2 }}$ and $\mathrm{T}_{\mathrm{d} \text {-post4 }}$ returned promptly to pretreatment values (figs $\mathrm{l}$ and 2). In contrast, urine Dpd concentration was only slightly lower at the end of the dexamethasone course, and thereafter 


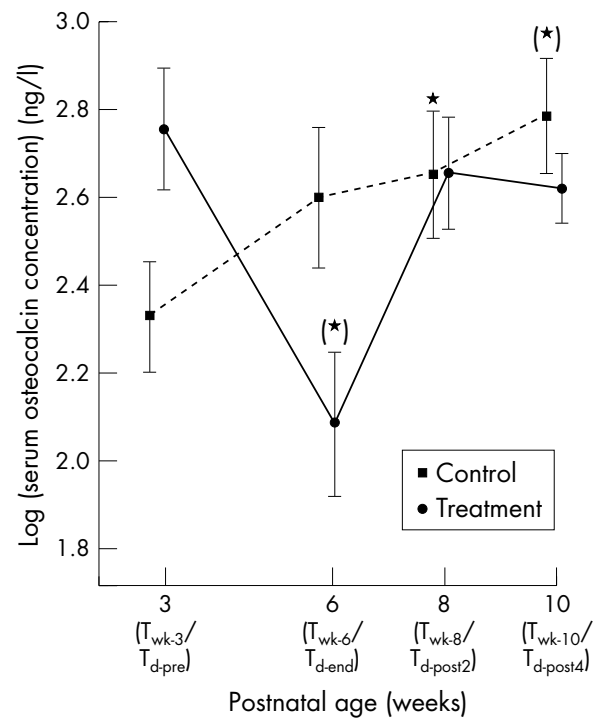

Figure 2 Serum osteocalcin concentrations $\left(\mathrm{ng} / \mathrm{l} ; \log _{\mathrm{e}}\right)$ in very low birthweight infants receiving corticosteroid or not over the study period. The asterisks indicate significant increase or decrease in serum osteocalcin concentration compared with the pretreatment $\left(T_{d \cdot r e r}\right)$ or week $3\left(T_{w k \cdot 3}\right)$ levels within the same group. The parentheses indicate a significant difference in serum osteocalcin concentration between the two groups when the corresponding time periods are compared. Results are expressed as mean and SEM.

at $\mathrm{T}_{\mathrm{d} \text {-post2 }}$ and $\mathrm{T}_{\mathrm{d} \text {-post4 }}$ it was significantly increased above the pretreatment value ( $\mathrm{p}<0.05$ and $\mathrm{p}<0.005$, respectively; fig 3 ). In addition, rates of increase in lower leg length were significantly increased in the period after treatment $\left(\mathrm{T}_{\mathrm{d}-\mathrm{end}}-\mathrm{T}_{\mathrm{d}-\mathrm{post2}}\right.$ and $\left.\mathrm{T}_{\mathrm{d}-\text { post } 2}-\mathrm{T}_{\mathrm{d} \text {-post } 4}\right)$ compared with during treatment $\left(\mathrm{T}_{\mathrm{d} \text {-pre }}-\mathrm{T}_{\mathrm{d} \text {-end }}\right)$ $(\mathrm{p}<0.0001$ and $\mathrm{p}<0.0001$ respectively $)$.

\section{Non-treatment group}

Serum BALP and osteocalcin and urinary Dpd concentrations increased significantly with advancing postnatal age. Serum BALP concentrations at week $6\left(\mathrm{~T}_{\mathrm{wk}-6}\right), 8\left(\mathrm{~T}_{\mathrm{wk}-8}\right)$, and $10\left(\mathrm{~T}_{\mathrm{wk}-10}\right)$ were significantly raised compared with that at week $3\left(\mathrm{~T}_{\mathrm{wk}-3}\right)$ $(\mathrm{p}<0.05, \mathrm{p}<0.0001$, and $\mathrm{p}<0.0001$ respectively; fig 1$)$. Similarly, serum osteocalcin concentrations at week $8\left(\mathrm{~T}_{\mathrm{wks}}\right)$ and $10\left(\mathrm{~T}_{\mathrm{wk}-10}\right)$ were significantly raised compared with the week $3\left(\mathrm{~T}_{\mathrm{wk}-3}\right)$ level $(\mathrm{p}<0.05$ and $\mathrm{p}<0.005$ respectively; fig 2$)$. Moreover, urinary Dpd concentrations at week $6\left(\mathrm{~T}_{\mathrm{wk-6}-6}\right), 8\left(\mathrm{~T}_{\mathrm{wk}-}\right.$ $\left.{ }_{8}\right)$, and $10\left(\mathrm{~T}_{\mathrm{wk}-10}\right)$ were significantly increased compared with the level at $\mathrm{T}_{\mathrm{wk}-3}(\mathrm{p}<0.05, \mathrm{p}<0.05$, and $\mathrm{p}<0.0001$ respectively; fig 3). The rate of increase in lower leg length, however, did not change significantly over the first 10 weeks of life in the non-treatment group (fig 4).

\section{Between group comparison}

When the pretreatment concentrations of the bone markers of the corticosteroid group were compared with their corresponding levels at week 3 of postnatal age in the nontreatment group, only serum BALP was significantly higher in dexamethasone treated infants $(\mathrm{p}<0.05)$. However, serum BALP concentration in the subsequent weeks $\left(\mathrm{T}_{\mathrm{wk}-6} v \mathrm{~T}_{\mathrm{d}-\text { end }}, \mathrm{T}_{\mathrm{wk}-8}\right.$ $v \quad \mathrm{~T}_{\mathrm{d}-\text { post2 }}, \mathrm{T}_{\text {wk-10 }} \quad v \quad \mathrm{~T}_{\mathrm{d} \text {-post4 }}$ ) were significantly lower in the corticosteroid group than in the non-treatment group $(\mathrm{p}<0.0005, \mathrm{p}<0.001$, and $\mathrm{p}<0.0001$ respectively; fig 1$)$. Serum osteocalcin concentration was also significantly higher at $\mathrm{T}_{\mathrm{wk}-6}$ and $\mathrm{T}_{\mathrm{wk}-10}$ in the non-treatment group than at $\mathrm{T}_{\mathrm{d} \text {-end }}$ and $\mathrm{T}_{\mathrm{d} \text {-post4 }}$ in the corticosteroid group $(\mathrm{p}<0.0001$ and $\mathrm{p}<0.05$ respectively; fig 2). Urinary Dpd concentration at the end of dexamethasone treatment was significantly lower than the corresponding urinary concentration at week 6 of the non-treatment group ( $\mathrm{p}<0.01$; fig 3 ). In addition, the rate of

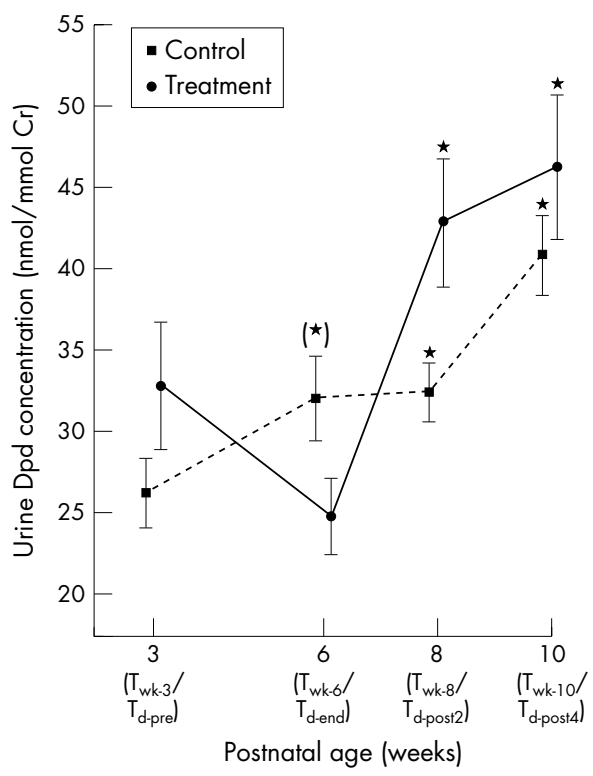

Figure 3 Creatinine adjusted urinary deoxypyridinoline (Dpd) concentrations $(\mathrm{nmol} / \mathrm{mmol} \mathrm{Cr}$ ) in very low birthweight infants receiving corticosteroid or not over the study period. The asterisks indicate a significant increase or decrease in creatinine adjusted urinary Dpd concentration compared with the pretreatment $\left(T_{\text {d.pre }}\right)$ or week $3\left(T_{\text {w.: }}\right)$ levels within the same group. The parentheses indicate a significant difference between the two groups when the corresponding time periods are compared. Results are expressed as mean and SEM.

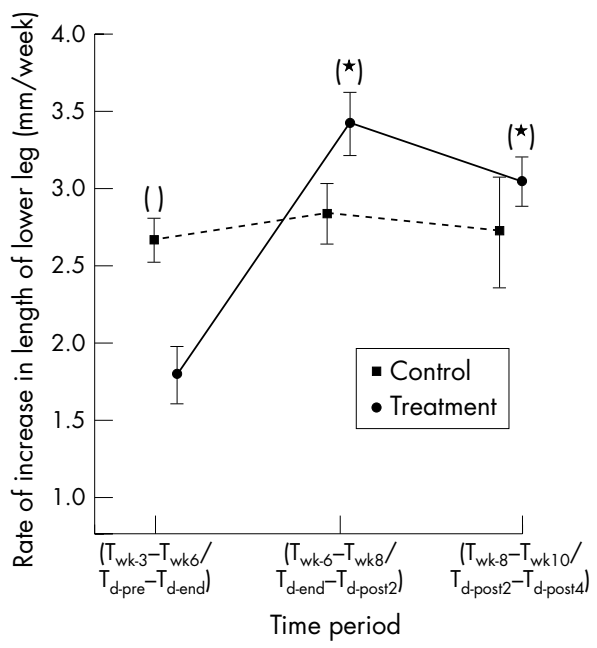

Figure 4 Rate of increase in the length of the lower leg $(\mathrm{mm} /$ week) in very low birthweight infants receiving corticosteroid or not over the study period. The asterisks indicate a significant increase or decrease in growth of the lower leg compared with the treatment period ( $\left.T_{\text {d.pre }}-T_{\text {dend }}\right)$ or week 3-6 of postnatal age $\left(T_{\text {wk. } 3}-T_{\text {wk. }-6}\right)$ within the same group. The parentheses indicate a significant difference between the two groups when the corresponding time periods are compared. Results are expressed as mean and SEM.

increase in the lower leg length was significantly higher in the non-treatment group between week 3 and $6\left(T_{w k-3}-T_{w k-6}\right)$ than in the corresponding period $\left(\mathrm{T}_{\mathrm{d} \text {-pre }}-\mathrm{T}_{\mathrm{d} \text {-end }}\right)$ of the corticosteroid group $(p<0.005)$. The mixed effects models also showed a significant difference in velocities in the periods after treatment $\left(\mathrm{T}_{\mathrm{d}-\mathrm{end}}-\mathrm{T}_{\mathrm{d} \text {-post2 }} v \mathrm{~T}_{\mathrm{wk}-6}-\mathrm{T}_{\text {wk-8 } 8}\right.$ and $\left.\mathrm{T}_{\mathrm{d} \text {-post2 }}-\mathrm{T}_{\mathrm{d}-\text { post } 4} v \mathrm{~T}_{\mathrm{wk}-8}-\mathrm{T}_{\text {wk-10 }}\right)$ between the two groups ( $\mathrm{p}<0.005$; fig 4$)$. When the above comparisons are adjusted for gestational age and duration of mechanical ventilation, oxygen dependency, and hospital stay, all aforementioned significant results between the two groups remain unaffected. 


\section{DISCUSSION}

Both markers of bone formation and resorption showed a progressive increase in concentration with advancing postnatal age in preterm infants who did not receive systemic corticosteroid treatment. The pattern suggests an increase in bone turnover during the early neonatal period. Several recent studies have shown similar changes in markers of bone metabolism in preterm infants. Bhandari et a $l^{12}$ showed a progressive increase in the concentrations of serum $\mathrm{C}$ terminal propeptide of type I collagen and BALP in the neonatal period. Ward and his colleagues also showed a similar positive pattern with osteocalcin. ${ }^{13}$ Moreover, Naylor and his investigating team showed a significant increase in serum concentrations of osteocalcin and urinary pyridinium cross links in preterm infants in the first three weeks of life. ${ }^{14}$ The findings of Tsukahara et al, ${ }^{15}$ which were similar to our results, also showed that the mean concentrations of urine pyridinoline and Dpd at 30 days of postnatal age were significantly higher than those at day 7. Although Crofton and co-workers showed a significant trend of postnatal increase in markers of collagen synthesis, this was coupled with a decrease in concentrations of markers of collagen breakdown within the same period. ${ }^{16}$ The discrepancy in results on urinary bone markers between different studies ${ }^{14-16}$ may be attributable to the relatively small sample size in each study, the wide variation in concentrations of urinary markers, the wide margin of errors of spot urine specimens as these measurements were required to be standardised by correcting the urinary concentration with creatinine, and possibly also the influence of circadian variation in bone metabolism. Thus accumulating evidence, ${ }^{12-16}$ including our current study, indicates that markers of bone formation increase progressively with postnatal age, and the net increase in bone growth during the early neonatal period (fig 4) supports the notion that there is dynamic osteoblastic activity and rapid bone formation during this period.

As corticosteroid is of proven value in facilitating weaning from mechanical ventilation in preterm infants ${ }^{7}$ and BPD is known to be more prevalent in patients of lower gestation, it is not possible to select a perfect control group without a randomised study, which is now no longer considered ethical to perform. Thus the best available approach is to compare the bone markers before and after dexamethasone treatment in corticosteroid treated patients, and also to compare the serum and urinary concentrations of bone markers of corticosteroid treated infants with those of non-treated infants with similar clinical characteristics and at comparable postnatal ages. Our results indicate that exposure of preterm VLBW infants to high dose systemic dexamethasone results in a significant decrease in serum concentrations of BALP and osteocalcin (fig 1 and 2), and suggest inhibition of bone formation. In vitro experiments have also shown considerable suppression of human osteoblastic cell function and DNA synthesis by dexamethasone and methylprednisolone. ${ }^{17}$ Similarly, the use of systemic corticosteroid in adult patients with rheumatoid arthritis has been associated with negative short term effects on bone formation, whereas markers of bone resorption remained unchanged or decreased. ${ }^{56}$ In contrast, Crofton et $a l^{18}$ in a recent study suggested an increase in plasma BALP concentration in preterm infants who received dexamethasone for treatment of BPD. However, only a small number of subjects $(\mathrm{n}=14)$ were investigated, the response of BALP to corticosteroid was highly variable among patients, and the study only showed a non-significant positive trend. Although urinary Dpd concentration at the end of the dexamethasone course $\left(T_{d-e n d}\right)$ had not decreased significantly from the pretreatment level $\left(\mathrm{T}_{\mathrm{d}-\mathrm{pre}}\right)$, the concentration at $\mathrm{T}_{\mathrm{d} \text {-end }}$ was significantly lower than the corresponding level at week 6 $\left(\mathrm{T}_{\mathrm{wk}-6}\right)$ in the non-treatment group (fig 3). The overall results therefore suggest that the use of systemic dexamethasone in preterm infants reduces bone turnover and metabolism. How- ever, as the rate of increase in lower leg length was significantly lower during dexamethasone treatment $\left(\mathrm{T}_{\mathrm{d} \text {-pre }}-\mathrm{T}_{\mathrm{d} \text { - }}\right.$ end ) than after treatment $\left(\mathrm{T}_{\mathrm{d}-\mathrm{end}}-\mathrm{T}_{\mathrm{d}-\text { post2 }}\right.$ and $\mathrm{T}_{\mathrm{d} \text {-post2 }}-\mathrm{T}_{\mathrm{d} \text {-post4 }} ;$ fig 4$)$ and also when compared with that in the corresponding period $\left(\mathrm{T}_{\mathrm{wk}-3}-\mathrm{T}_{\mathrm{wk}-6}\right)$ of the non-treatment group, we speculated that corticosteroid slowed down bone formation more than bone resorption. This hypothesis was further supported by the fact that bone mineral content measured by dual energy $x$ ray absorptiometry was significantly lowered in dexamethasone treated infants. ${ }^{13}$ Our results also show that the effects of systemic corticosteroid on bone growth and metabolism were transient, as catch up bone growth was apparent in the immediate period after the end of dexamethasone treatment (fig 4).

It has been proposed that corticosteroid inhibits bone collagen synthesis by suppressing the expression of osteoblastic genes, including the COL $1 \mathrm{Al}$ and osteocalcin genes, ${ }^{19}$ and prevents the normal nocturnal surge of osteocalcin in humans. ${ }^{20}$ This results in interruption of osteoblastic function, decreases cell replication, reduces differentiation of osteoblast progenitors, and disrupts the organisation of new osteoblast attachment to the osteoid surface. ${ }^{21}$ In addition, exogenous corticosteroid decreases $\beta 1$ integrin expression of osteoblasts, ${ }^{22} 23$ reduces the affiliation of osteoblasts with extracellular matrix protein, ${ }^{23}$ and decreases the calcification of newly synthesised matrix. ${ }^{21}$ Hence, the negative effect of long term corticosteroid usage may cause a decrease in bone length, trabecular bone volume, and bone mineral content. ${ }^{24}$

During the study, we also collected data on the daily nutritional intake including parenteral nutrition, daily milk consumption, and supplementation with vitamins and phosphate. There was no significant difference in the age at which full enteral feeding was achieved and the time at which oral vitamin and mineral supplements were introduced between the two groups (table 1). Changes in concentrations of bone markers in dexamethasone treated infants were, however, not affected by energy intake or supplementation with vitamins and phosphate. Thus the close temporal association between the change in levels of bone markers and the use of dexamethasone strongly suggests a causal relation (figs 1-3).

In summary, we have shown that both serum concentrations of BALP and osteocalcin and urinary concentrations of Dpd increase significantly with advancing postnatal age, indicating an increase in bone turnover and rapid bone growth during the early neonatal period. In contrast, dexamethasone causes appreciable suppression of markers of bone formation and to a lesser extent also of bone resorption, resulting in inhibition of bone formation. The negative effect of dexamethasone on biochemical bone markers is, however, transient and serum levels of BALP and osteocalcin promptly return to pretreatment levels two weeks after the end of dexamethasone treatment. This study therefore provides further evidence that systemic corticosteroid inhibits bone growth mainly by decreasing bone formation, and this process is reversible after the medication is withdrawn.

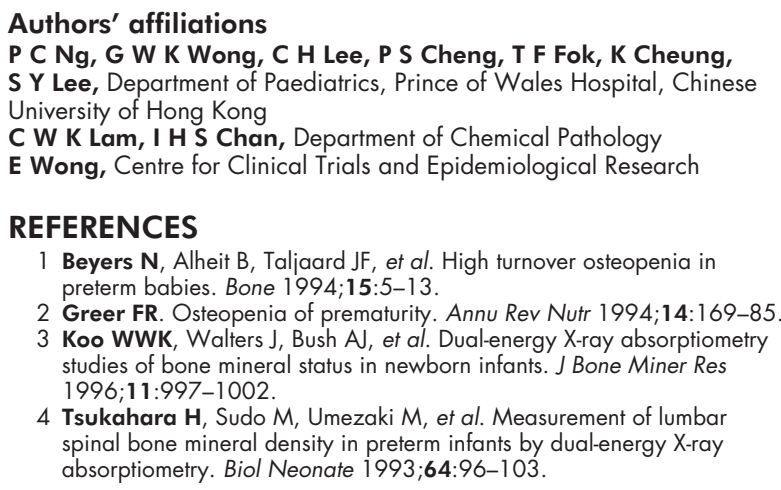

4 Tsukahara $\mathbf{H}$, Sudo $M$, Umezaki $M$, et al. Measurement of lumbar spinal bone mineral density in preterm infants by dual-energy $\mathrm{X}$-ray absorptiometry. Biol Neonate 1993;64:96-103. 
5 Lems WF, Gerrits MI, Jacobs JWG, et al. Changes in (markers of) bone metabolism during high dose corticosteroid pulse treatment in patients with rheumatoid arthritis. Ann Rheum Dis 1996;55:288-93.

6 Lems WF, Jacobs JWG, van den Brink HR, et al. Transient decrease in osteocalcin and markers of type 1 collagen turnover during high-dose corticosteroid pulse therapy in rheumatoid arthritis. Br J Rheumatol 1993;32:787-9.

$7 \mathrm{Ng}$ PC. The effectiveness and side-effects of dexamethasone in preterm infants with bronchopulmonary dysplasia. Arch Dis Child

1993:68:330-6.

8 Akesson K. Biochemical markers of bone turnover: a review. Acta Orthop Scand 1995;66:376-86.

9 Behe W, Barnet J. Quantification of bone alkaline phosphatase in serum by precipitation with wheat-germ lectin: a simplified method and its clinical plausibility. Clin Chem 1986;32:1960-6.

10 Gibson AT, Pearse RG, Wales JKH. Knemometry and assessment of growth in premature babies. Arch Dis Child 1993;69:498-504.

11 Goldstein H. Multilevel statistical models. In: Kendall's library of statistics 3. London: Edward Arnold, 1995:87-94.

12 Bhandari V, Fall P, Raisz L, et al. Potential biochemical growth markers in premature infants. Am J Perinatol 1999: 16;339-49.

13 Ward WE, Atkinson SA, Donovan SM, et al. Bone metabolism and circulating IGF-1 and IGFBPs in dexamethasone-treated pretem infants. Early Hum Dev 1999;56:127-41.

14 Naylor KE, Eastell R, Shattuck KE, et al. Bone turnover in preterm infants. Pediatr Res 1999;45:363-6.

15 Tsukahara H, Takeuchi M, Fujisawa K, et al. High-turnover osteopenia in preterm infants: determination of urinary pyridinium cross-links of collagen. Metabolism 1998;47:333-5.
16 Crofton PM, Shrivastava A, Wade JC, et al. Bone and collagen markers in preterm infants: relationship with growth and bone mineral content over the first 10 weeks of life. Pediatr Res 1999;46:581-7.

17 Kasperk C, Schneider U, Sommer U, et al. Differential effects of glucocorticoids on human osteoblastic cell metabolism in vitro. Calcif Tissue Int 1995;57:120-6.

18 Crofton PM, Shrivastava A, Wade JC, et al. Effects of dexamethasone treatment on bone and collagen turnover in preterm infants with chronic lung disease. Pediatr Res 2000;48:155-62.

19 Advani S, LaFrancis D, Bogdanovic E, et al. Dexamethasone suppresses in vivo levels of bone collagen synthesis in neonatal mice. Bone 1997;20:41-6.

20 Nielsen HK, Charles P, Mosekilde L. The effect of single oral doses of prednisolone on the circadian rhythm of serum osteocalcin in normal subjects. J Clin Endocrinol Metab 1998;67:1025-30.

21 Gronowicz GA, DeRome ME, McCarthy MB. Glucocorticoids inhibi fibronectin synthesis and messenger ribonucleic acid levels in cultured fetal rat parietal bones. Endocrinology 1991;128:1107-14.

22 Doherty WJ, DeRome ME, McCarthy MB, et al. The effect of glucocorticoids on osteoblast function: the effect of corticosterone on osteoblast expression of beta-1 integrins. J Bone Joint Surg [Am] 1995; 77:396-404.

23 Gronowicz GA, McCarthy MB. Glucocorticoids inhibit the attachment of osteoblasts to bone extracellular matrix proteins and decrease $\beta 1$-integrin levels. Endocrinology 1995;136:598-608.

24 Altman A, Hockberg Z, Silbermann M. Interactions between growth hormone and dexamethasone in skeletal growth and bone structure of the young mouse. Calcif Tissue Int 1992:51:298-304. 